\title{
Promotional Tools: Household Marketing Strategy and Its Effectiveness
}

\author{
Md.Shahin Alam Khan ${ }^{1}$ \\ ${ }^{1}$ Shahjalal University of Science \& Technology, Sylhet, Bangladesh \\ Correspondence: Md.Shahin Alam Khan, Shahjalal University of Science \& Technology, Sylhet, Bangladesh.
}

Received: October 22, 2018

Accepted: December 8, 2018

Online Published: June 24, 2019

doi:10.5430/bmr.v8n2p32

URL: https://doi.org/10.5430/bmr.v8n2p32

\begin{abstract}
For any organizations, it is necessary to examine whether its marketing activities are enough to attract customers. The main objective of this study is to focus on the effectiveness of promotional tools of paintings industries.This research has done on the Roxy Paints Bangladesh Ltd. Every company employs their at best efforts to attract customer and to keep potential customer satisfied through their proper household marketing activities and tools. The effectiveness of these efforts depends on how the customer viewing the ads, how they remind advertisements in time of searching and purchasing the products. This report is based on some documents and also some practical observations. The nature of this study is exploratory and descriptive. All the issues intended to this study are explored through assessing and analyzing information those are gathered from different sources.
\end{abstract}

Keywords: household, marketing strategy, effectiveness

\section{Introduction}

In case of paint marketing companies and marketers have to consider the diverse factors and forces. To attract the customer toward the products, marketers must have to think what features of household marketing strategy is appealing to the householders. Traditional ways of household marketing is no longer to work because of increasing competition among the competitors. As a result, in the severer degradation of consumer confidence, marketers, category and brand managers are finding that the type of household marketing strategies that have served them well in the past, are no longer as effective. Measuring the effectiveness of the household marketing strategy is a critical element in the household marketing planning process. Research allows the marketing manager to evaluate the performance of specific program elements and provides input into the next period's situation analysis. It is a necessary ingredient to a continuing planning process, yet it is often not carried out. Marketers think that assessing the effectiveness of ads both before they are implemented and after the final versions have been completed and fielded offers a number of advantages such as avoiding costly mistakes, evaluating alternative strategies, increasing the efficiency of advertising in general, determining if objectives are achieved. Most recent it is noticeable that customers and environment activists are more concern about the different impacts of paints ingredients on environment and public. When a young child is exposed to lead, the harm to her or his nervous system makes it more likely that the child will have difficulties in school and engage in impulsive and violent behavior.

\section{Literature Review}

It is believed that this study would help several parties to know and understand some practical matters, and which will help them to formulate their household marketing policies and strategies for advertising new products and communicating with potential customers. Institutions like locals or multinationals, researchers, students, individuals, etc. will be benefited from this study. If anyone wants to know which household marketing strategies is most important for the paint marketing and how these impact both organization and customers learning's about the products, then they can take help from this study. If anyone wants to know the factors which should be considered in case of formulating a strategy, they can take help from here. Particularly, it will be very helpful for Roxy Paints in various ways. However, the alleged scopes are:

- It will help organizations in choosing appropriate household marketing policies to advertise their products (Paints).

- It will provide a proper idea about the customers willingness and interests about the advertisements of the company. 
- It will help the organization to access how household marketing strategies \& activities influence customer understandings and learning.

\section{Marketing}

Marketing is the action or process of promoting and selling products or services, including market research and advertising.In broadly, The management process through which goods and services move from concept to the customer. It includes the coordination of four elements called the 4 P's of marketing:

- identification, selection and development of a product

- determination of its price

- selection of a distribution channel to reach the customer's place, and

- development and implementation of a promotional strategy

\section{Marketing Strategy}

A marketing strategy is a process or model to allow a company or organization to focus limited resources on the best opportunities to increase sales and thereby achieve a sustainable competitive advantage. Marketing strategy has the fundamental goal of increasing sales and achieving a sustainable competitive advantage.

\subsection{Household Marketing}

A household consists of one or more people who live in the same dwelling and also share at meals or living accommodation, and may consist of a single family or some other grouping of people.Today we live in the era of modern world.In this modern world Household Marketing is one of the majors way marketing of products.A household marketing is a process of marketing/exposing of one's products to the householders for buying their products.

\section{Household Marketing Strategies}

Household marketing strategy is a method of marketing by which one can marketize their products on the basis of households.Roxy Paint Ltd. has some household marketing strategies.These are following below;

- Household Relationship Strategy

- $\quad$ Advertising Strategy

- $\quad$ Selling Strategy

- $\quad$ Product Perceived Quality Strategy

- $\quad$ Guiding Strategy

\subsection{Household Relationship Strategy}

Household relationship is a way by which one can marketize their products to the householders.It is possible to convince householders to buy their products by making a good relationship with the householders. Roxy Paint Ltd has taken this kind of relation making strategy like as household relation.Roxy Paint Ltd made this Household relation by ensuring these;

- Offering free services

- Providing transportations

- Well customer behavior

- $\quad$ Providing suggestions

\subsection{Advertising}

Advertising (or advertizing) is a form of marketing communication used to promote or sell something, usually a business's products or services. Roxy Paint Ltd has some advertising policies for the households. All of these the major advertising policies are given below;

- $\quad$ TV Advertisements

- $\quad$ Social Network Advertisements

- Banner

- Exhibitions 


\subsection{Selling Strategy}

Selling is the ultimate target of any company.The success of one's company's mainly depends on the best selling and making profits. In this perspective Roxy Paint Ltd has been taking some selling strategies. By implementing these selling strategies Roxy could increase their total sales. Before increasing total sales Roxy Paint Ltd had to ensure these;

- High Quality products

- Lower prices

- Attractiveness

- Durabilties

- Well packaging

5.4 Perceived Quality Strategy

Product perceived quality is the qualities of products to satisfy the customers after purchasing the products. Products perceived quality is mainly depend on the high quality of the products.Roxy Paint Ltd has this quality of products.In order to increase the product qualities Roxy has taken some steps;

- High quality

- Well production

- Durabilties

\subsection{Guideline Strategy}

Guiding strategy is a way of increasing the overall performance of the company.In this stage a company has to provide extra facilities for the customers. Roxy Paint Ltd is also providing some extra advantages to the customers,such as;

- $\quad$ Providing Architect Suggestions

- Computerized visualizations

- Artificial color making facilities

- Information about different products

5.6 Household Marketing Strategies of Roxy Paints

Household Marketing strategies of Roxy Paint Ltd. are built on STP - Segmentation, Targeting and Positioning. Roxy discovers different needs and different class of people in the market place, target those needs and class of people that it can satisfy in a proper way and then position its offerings, so that the target market can recognize the company's distinctive offerings and images. Household Marketing strategies of Roxy depend on: Segmentation of products.

5.6.1 Product Segmentation

Roxy paints mainly segmented its products based on the Three broad categorizes ;

- Decorative Paints

- Industrial Paints

- Marine Paints

\section{Decorative:}

\section{Water based product}

- Distemper

- $\quad$ Plastic

- Weather guard

- Water sealer

- Wall Putty

- Wall care

\section{Oil based product}

- $\quad 777$ high gloss synthetic enamel 
- Butterfly synthetic enamel

\section{Industrial Paints}

- $\quad$.Roxy industrial paint

\section{Marine Paints}

- Roxy sea guard

- Roxy marine

\section{Other products}

- Best copal varnish

- Synthetic clear varnish

- Butterfly copal varnish

\section{Design paints:}

\section{- Roxy fusion}

\subsubsection{Target Market Selection Strategies}

Roxy Paint Ltd. has chosen target markets to co-operate in the interest of the overall company in a socially responsible manner. The total size of the paint industry in Bangladesh is estimated at taka $1537 \mathrm{cr}$. in the year 2012 . The paint industry can be divided into three segments. These are
A) Decorative.
B) Industrial.
C) Marine.

The decorative segments of the market accounts for a whopping $83 \%$ of the total industry, whereas industrial, marine segments contribute $12 \%$, and other special products $5 \%$, respectively.

The main focus of the companies, operating in the industry, is towards decorative segment. Only a few of the companies have their products offerings in industrial and marine segments. All the competitors are concentrating their best efforts for carving out their share of the pie in the decorative segment of the industry. The enamel segment accounts for around $50 \%$ of the decorative paint market by value and approximately $40 \%$ by volume.

The market share Roxy in the synthetic enamel category is increasing nowadays. As this product is accountable for the major share of the paint market, its continued success will result in significant growth of the overall market share of the company. This will also enable Roxy to battle its competitors by weakening then in such a strategically important segment.

\section{Analysis Of Employees Data:}

\begin{tabular}{lll}
\hline & No. of employees & $\%$ of employees \\
\hline Advertising & 4 & 40 \\
Personal selling & 3 & 30 \\
Servicing Center & 2 & 20 \\
Household relations & 1 & 10 \\
\hline
\end{tabular}

Figure 1. Medium Household Marketing Strategies.

Interpretation: The above graph shows that $40 \%$ of employees argue on behalf of using advertisements as medium of household marketing strategies, $30 \%$ personal selling and $20 \%$ use sales promotion and the $10 \%$ is household relations. 


\begin{tabular}{llll}
\hline & Reasons & $\begin{array}{l}\text { No. } \\
\text { employees }\end{array}$ & $\begin{array}{l}\text { of } \\
\text { employees }\end{array}$ \\
\hline Advertising & Cost effective & 1 & 10 \\
Advertising & $\begin{array}{l}\text { Greater customer } \\
\text { access }\end{array}$ & 3 & 30 \\
Personal selling & Prompt response & 3 & 30 \\
Servicing Center & Easy to manage & 3 & 30
\end{tabular}

Figure 2. Reasons of using medium Household Marketing Strategy

Interpretation: Among 5 employees (50\% total employees) who use advertising 30\% use it as it has greater customer access, $20 \%$ use as it is cost effective, among rest $50 \%$; $30 \%$ use personal selling for prompt responses and $20 \%$ use sales promotion because it is easy to manage

\begin{tabular}{lll}
\hline Strategies & No. of employees & $\%$ of employees \\
\hline Sales promotion & 6 & 60 \\
Personal selling & 4 & 40 \\
\hline
\end{tabular}

Figure 3. Strategy for increasing sales

Interpretation: Above graphical explanation says that $60 \%$ employees use sales promotion strategy to increase sales volume and rest $40 \%$ use personal selling

\begin{tabular}{lll}
\hline Types & \% of employees & \% of personal selling \\
\hline Sales representative & 30 & 75 \\
Agents & 10 & 25 \\
Sales consultants & 0 & 00 \\
\hline
\end{tabular}

Figure 4. Types of Personal Selling

Interpretation: Among 40\% total employees who use personal selling 30\% use sales representatives and rest $10 \%$ use agents that is the percentage of personal selling respectively 75 and 25 .

\begin{tabular}{lll}
\hline Tools & No. of employees & $\%$ of employees \\
\hline Price reduction & 2 & 20 \\
Innovate new products and ideas & 5 & 50 \\
Quality improvement & 3 & 30 \\
Money back guarantee & 0 & 00
\end{tabular}

Table 5.Tools used to attract competitor's customer

Interpretation: To attract the competitors customer $20 \%$ employees think price reduction is effective, $50 \%$ think it need to innovate new products and ideas to attract customers customer and rest $30 \%$ emphasis on quality improvement.

5.7 Analysis of Viewers Data

\begin{tabular}{lll}
\hline Medium & No. of Viewers & \% of Viewers \\
\hline TV & 10 & 33.33 \\
Mobile & 6 & 20 \\
Print & 8 & 27 \\
Internet & 4 & 13.33
\end{tabular}

Figure 6. Preference of media 
Interpretation: More than $33 \%$ ad viewers prefer to receive ad through TV commercial because they think it is more visual then others, $20 \%$ ad viewers prefer to receive via mobile phone ad as they think it is easy and available, $27 \%$ ad viewers are prefer print media as it easy to understand and rest $13 \%$ prefer internet as it available anywhere.

\begin{tabular}{llll}
\hline Indicator & Points & No. of viewers & \% viewers \\
\hline Best & 5 & 6 & 20 \\
Better & 4 & 9 & 30 \\
Same & 3 & 5 & 16.67 \\
Worse & 2 & 7 & 23.33 \\
Worst & 1 & 3 & 10 \\
\hline
\end{tabular}

Figure 7. Comparison of advertisement

Interpretation: $20 \%$ viewers think this ad is better than others that they seen before, 30 think it is best, $16.67 \%$ are neutral or same, $23.33 \%$ think worse and rest 10 think it is worst.

\begin{tabular}{lll}
\hline Slogans & No. of viewers & \% of viewers \\
\hline Coloring since 1950 & 7 & 23.33 \\
Coloring since 1954 & 6 & 20 \\
Coloring since1953 & 13 & 43.33 \\
Coloring since 1955 & 4 & 13.33 \\
\hline
\end{tabular}

Figure 8. Slogan of Roxy Paints

Interpretation: From above we can state that 23\% viewers say the slogan of Roxy Paints is coloring since 1950, 20\% say coloring since 1994, 44\% say coloring since 1953 that is correct and rest 13\% say coloring since 1955 .

\begin{tabular}{llll}
\hline Indicator & Points & No. of customer & $\%$ Customer \\
\hline Strongly agree & 5 & 3 & 10 \\
Agree & 4 & 7 & 23.33 \\
Neutral & 3 & 8 & 26.67 \\
Disagree & 2 & 9 & 30 \\
Strongly disagree & 1 & 3 & 10
\end{tabular}

Figure 9. " Rong Bolte Roxy" do you agree with this statement

Interpretation: 10\% viewers strongly agree with the statement "Rong Bolte Roxy", $23.33 \%$ agree, $26.67 \%$ neutral,30\% disagree and rest $10 \%$ strongly disagree

\begin{tabular}{lll}
\hline Focus points & No of viewers & \% of viewers \\
\hline Cost & 15 & 50 \\
Service & 3 & 10 \\
Quality & 8 & 26.67 \\
Loyalty & 4 & 13.33 \\
\hline
\end{tabular}

Figure 3.2.6 Focus point of the ad (ad 2)

Interpretation: the above tools represent that $50 \%$ viewers assume that the focus point of advertisements is the cost that is correct, $10 \%$ assume service, $26.67 \%$ assume quality and $13.33 \%$ assume loyalty 


\begin{tabular}{lll}
\hline Products & No of viewers & \% of viewers \\
\hline $\begin{array}{l}\text { Fusion and } \\
\text { weather guard }\end{array}$ & 14 & 46.67 \\
Water cellar & 7 & 23.33 \\
SPD \&APD & 3 & 10 \\
Wall putty & 6 & 20
\end{tabular}

Figure 10. Opinions regarding advertising products (ad 3)

Interpretation: From above, we can see $46.67 \%$ ad viewers say this ad about fusions and weather guard of Roxy Paint that is correct, $23.33 \%$ say water cellar, $10 \%$ say SPD and APD and rest $20 \%$ say wall putting

\begin{tabular}{lll}
\hline Purposes & No of viewers & \% of viewers \\
\hline Attain customer reliability & 15 & 50 \\
To attain loyalty & 8 & 26.67 \\
To attract customers & 4 & 13.33 \\
Increase service & 3 & 10
\end{tabular}

Figure 11. Purpose of the ad (L2)

Interpretation: $50 \%$ viewers think that purpose of the ad is to attain reliability of customer, $26.67 \%$ think to attain loyalty, $13.33 \%$ think to attract customer and rest $10 \%$ think to increase service.

\begin{tabular}{lll}
\hline No. Services & No. of viewers & \% of viewers \\
\hline 5 & 5 & 16.67 \\
4 & 9 & 30 \\
3 & 10 & 33.33 \\
2 & 6 & 20 \\
\hline
\end{tabular}

Figure 12. Free of cost services of Roxy 3C (L3)

Interpretation: $16.67 \%$ viewers remember 5 (all) cost free services of Roxy 3C, 30\% remember 4 cost free services of Roxy 3C, 33.33\% remember 3 cost free services of Roxy 3C and rest 20\% remember 2 cost free services of Roxy 3C.

\subsection{Findings of the Study}

For any research work, it is necessary to draw a summary of findings because it helps the readers and beneficiaries to realize the most outstanding achievement from the study and the actual scenario of the study area. As the focus point of this study is to measure effectiveness of promotional tools of Roxy Paints so the findings highlighted viewers opinions regarding different promotional efforts taken by companies. The major findings of our research are presented below:

- $\quad$ Partly a larger portion of viewers (around 33.33\%) prefers TV commercial than other media where ineffective percentages of exposure is large.

- Only $44 \%$ viewers remember company and products, whereas $56 \%$ viewers cannot remember company's and product's name even ad also.

- Nearly 50\% viewers can recall slogan of Roxy Paints correctly.

- A small portion (23.33\%) of viewers agreed with the statement "Rong Bolte Roxy" a large portion of viewers (30\%) disagreed with the statement and $26.67 \%$ are neutral.

- Half portion of viewers can't trace the correct focus point of advertisements that is the cost of using Roxy products.

- Less than 50\% viewers say that ad 3 describes fusion and weather guard paints of Roxy Paints whereas $23.33 \%$ say water cellar, $10 \%$ say SPD \& APD and 30\% say wall putty.

- Only $16.67 \%$ viewers remember all (9) products of ad (L1P1 \& L2P2) on the other hand $30 \%$ remember 4 products, $13.33 \%$ remember 6 products and $40 \%$ remember 3 products. 
- Majority viewers (55\%) think that most important features of Roxy Paints are eco-friendly and smooth wall finish on contrary to $45 \%$ viewers think money back guarantee and highest coverage are most important.

- More than 63\% viewers express their opinion on behalf of Scholarship for student as CSR activities of Roxy paints.

- Very small portion (16.67\%) of viewers recalled all (5) free of cost services of Roxy 3C, $13.33 \%$ recalled 4 cost free services of Roxy 3C, $33.33 \%$ recalled 3 cost free services of Roxy $3 \mathrm{C}$ and rest $20 \%$ recalled 2 cost free services of Roxy 3C.

\section{Conclusion}

Although in developed countries the market of paints is highly saturated, but in Bangladesh this market is in the growth stage where per capita paints consumption is very low so there is a great probability of expanding business of Roxy Paints. On the other hand, in parallel with the development of country, resulting from increased per capita income people prefer luxurious paints and an extensive range of design of paints besides traditional paints so companies can take the opportunity of this.

Besides these, in Bangladesh there are great prospects of paints for several reasons, including growth in real estate sector, gradual increase in awareness of preservation of houses, widening urbanization, availability of house loans and shift from semi-permanent to permanent housing structure, growth in ship building industry and consistent growth of the economy at around 6 percent for the past five years.

It is much more important and critical work to find appropriate marketing strategies for Roxy Paints to attract its customer towards its products. How to develop a good marketing strategy in association with appropriate marketing mixes depends on the organizational structure and their products including sales forces. To receive the highest response from the customer, an effective customer driven marketing strategy must be equipped with knowledge of the existing marketing styles. To be market leader Roxy Paints has to concentrate in development of such promotional tools that is cost effective as well as convincing.

In spite of having some constraints, through designing and implementing proper promotional tools Roxy Paints will become pioneer in paints industry of Bangladesh by managing its rivalry.

\section{References}

Asian regional paint report. (2014). March 2014.

Gary W. Williams1, Oral Capps, Jr., and Marco A. Palma. Effectiveness of Marketing.

Neslin SA. (2002). Sales Promotion. Marketing Science Institute: Cambridge, MA.

Norwood McMillian, Stephen R. Lucas, BentonE. Miles. The determination of the effectiveness a marketing promotional activity. University of North Carolina at Greenboro, USA.

PromotionPrograms: The Case of Texas Citrus,Department of Agricultural Economics, Texas A \& M University, 458D Blocker Building, 2124 TAMU, College Station, TX 77843-2124.

Steenkamp J-BEM, Nijs VR, Hanssens DM, Dekimpe MG. (2005). Competitive reactions to advertising and promotion attacks. Marketing Science 2005; in press. https://doi.org/10.1287/mksc.1040.0069 